\title{
Product reformulation and nutritional improvements after new competitive food standards in schools
}

\author{
Jaquelyn L Jahn ${ }^{1, *}$, Juliana FW Cohen ${ }^{2,3}$, Mary T Gorski-Findling ${ }^{4}$, Jessica A Hoffman ${ }^{5}$, \\ Lindsay Rosenfeld ${ }^{6,7}$, Ruth Chaffee ${ }^{5}$, Lauren Smith ${ }^{8}$ and Eric B Rimm ${ }^{3,9}$ \\ 'Department of Social and Behavioral Sciences, Harvard T.H. Chan School of Public Health, Harvard University, \\ 677 Huntington Avenue, Boston, MA 02115, USA: ${ }^{2}$ Department of Health Sciences, Merrimack College, North \\ Andover, MA, USA: ${ }^{3}$ Department of Nutrition, Harvard T.H. Chan School of Public Health, Boston, MA, USA: \\ ${ }^{4}$ Department of Health Policy, Harvard Graduate School of Arts and Sciences, Harvard University, Cambridge, MA, \\ USA: ${ }^{5}$ Department of Counseling and Applied Educational Psychology, Institute on Urban Health Research and \\ Practice, Bouvé College of Health Sciences, Northeastern University, Boston, MA, USA: ${ }^{6}$ Institute on Urban Health \\ Research and Practice, Bouvé College of Health Sciences, Northeastern University, Boston, MA, USA: ${ }^{7}$ Heller School \\ of Public Policy, Brandeis University, Waltham, MA, USA: ${ }^{8}$ Department of Pediatrics, Boston University School of \\ Medicine, Boston, MA, USA: ${ }^{9}$ Channing Division of Network Medicine, Brigham and Women's Hospital and \\ Harvard Medical School, Boston, MA, USA
}

Submitted 13 June 2017: Final revision received 10 0ctober 2017: Accepted 20 0ctober 2017: First published online 21 December 2017

\begin{abstract}
Objective: In 2012, Massachusetts enacted school competitive food and beverage standards similar to national Smart Snacks. These standards aim to improve the nutritional quality of competitive snacks. It was previously demonstrated that a majority of foods and beverages were compliant with the standards, but it was unknown whether food manufacturers reformulated products in response to the standards. The present study assessed whether products were reformulated after standards were implemented; the availability of reformulated products outside schools; and whether compliance with the standards improved the nutrient composition of competitive snacks.

Design: An observational cohort study documenting all competitive snacks sold before (2012) and after (2013 and 2014) the standards were implemented.

Setting: The sample included thirty-six school districts with both a middle and high school.

Results: After 2012, energy, saturated fat, $\mathrm{Na}$ and sugar decreased and fibre increased among all competitive foods. By 2013, $8 \%$ of foods were reformulated, as were an additional $9 \%$ by 2014 . Nearly $15 \%$ of reformulated foods were look-alike products that could not be purchased at supermarkets. Energy and $\mathrm{Na}$ in beverages decreased after 2012, in part facilitated by smaller package sizes. Conclusions: Massachusetts' law was effective in improving the nutritional content of snacks and product reformulation helped schools adhere to the law. This suggests fully implementing Smart Snacks standards may similarly improve the foods available in schools nationally. However, only some healthier reformulated foods were available outside schools.
\end{abstract}

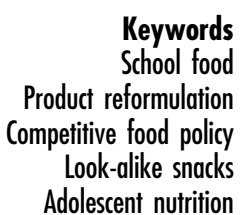

Keywords Shool food mpetitive food policy Look-alike snacks
The Healthy Hunger-Free Kids Act of 2010 enabled the US Department of Agriculture to set nutrition standards for all foods and beverages sold in schools ${ }^{(1)}$. This includes the Smart Snacks in Schools standards, which aim to improve the nutritional quality of competitive foods and beverages, which are snacks that are sold in schools outside the national school meals programmes. Traditionally, these competitive foods and beverages are high in energy, saturated fats and added sugars ${ }^{(2)}$. The Massachusetts nutritional standards include a limit on energy, total fat, saturated fat, $\mathrm{Na}$ and sugar; whole grain requirements for snacks; and portion limits for beverages. Updating competitive food standards is particularly useful to improve students' diets because they spend a significant amount of time at school and these snacks are readily available through à la carte lines, vending machines, school stores and sporting events ${ }^{(3)}$. Results from longitudinal observational studies suggest healthier competitive food policies have a beneficial impact on BMI and weight gain ${ }^{(4,5)}$. However, there is limited research on the 
effect of nutrition standards on the nutritional quality of competitive foods, or whether standards prompt food manufacturers to reformulate products.

Evidence from restaurant menu labelling policies and trans-fat package labelling suggest that policy changes encourage product reformulation. Results from studies of menu labelling in chain restaurants showed that restaurants reformulated entrées to be lower in energy, saturated fat and $\mathrm{Na}$ eighteen months after a county menu labelling law took effect and prompted fast-food chains to offer more healthful options ${ }^{(6,7)}$. Moreover, the labelling of trans-fat on the nutrition facts panel of packaged foods and beverages contributed to the near elimination of trans-fat from the US food supply ${ }^{(8,9)}$.

Before Smart Snacks standards were implemented nationally in the 2014-2015 school year, Massachusetts passed a law to develop strict state-wide nutrition standards for competitive foods and beverages starting in the 2012-2013 school year (Massachusetts Law 105 CMR $225.000)^{(10)}$. The Massachusetts law set standards that were very similar to the current Smart Snacks standards ${ }^{(11)}$ and evaluation of their effectiveness may help to predict how well the national policy will change the nutritional quality of competitive foods and industry response.

School food-service directors can effectively implement competitive foods laws if food manufacturers supply sufficient variety in compliant foods. Previous quantitative analyses showed that a majority of foods and beverages available for purchase after the standards were implemented were compliant ${ }^{(11,12)}$ and evaluated the impact of the standards on school food revenues ${ }^{(13)}$. These analyses did not examine whether food manufacturers improved the nutritional quality of the products. Moreover, qualitative interviews with school food-service directors point to the need for food manufacturers to supply and market compliant products $^{(14)}$. To do so, food manufacturers can either create new products that meet the competitive foods guidelines or reformulate existing products to meet the guidelines. Previous research has shown, however, that reformulated products that have similar-looking packaging with differing nutritional content confuse consumers and could potentially interfere with school messaging about good nutrition and health ${ }^{(15)}$. Therefore, the aims of the present analysis were to: (i) quantify the extent to which food manufacturers reformulated products to be compliant with the new law; (ii) determine whether reformulated products were available outside schools; and (iii) assess the extent to which the standards improved nutrient composition of snacks available in schools.

\section{Methods}

\section{Study population and follow-up}

The NOURISH (Nutrition Opportunities to Understand Reforms Involving Student Health) study recruitment and participation have been described previously ${ }^{(11)}$. The sample includes thirty-six school districts from Massachusetts, with one middle school and one high school in each district. Middle schools had a mean of 636 (SD 239) students, and high schools had a mean of 1019 (SD 502) students. Middle schools had a mean of $29 \cdot 6$ (SD 17.8) \% of students eligible for free or reduced-priced lunch, and high schools had a similar proportion (mean 24.7 (sD: 14.4) \%). The percentage of non-White students in middle schools was $19 \cdot 4$ (SD 16.2) \%, and high schools it was 19.1 (SD 16.7) \%.

The overall response rate for the present study was $32.7 \%$, and food-service directors were compensated with \$US 50 gift cards for their participation. At baseline (2012), thirty-seven districts agreed to participate, with nonconsenting districts citing time or availability constraints as reasons for non-participation. State-wide student testing requirements delayed data collection until late spring in each school year. One consenting school district was excluded from this analysis because of incomplete baseline data. Two school districts had a shared cafeteria between the middle and high school, so data were entered twice for these districts to reflect availability of foods to both middle- and high-school students. Follow-up visits were conducted during lunchtime of spring 2013 (twentyeight districts) and spring 2014 (twenty-one districts).

\section{Nutrition information}

Research assistants took digital photographs of all prepackaged competitive foods and beverages in à la carte lines in cafeterias, school stores and vending machines (inside and outside cafeterias) during lunchtime to identify product names and brands. Product availability was determined each year as the number of unique products offered per school. All pre-packaged foods and beverages and à la carte cookies baked by the school from packaged dough were included in the analyses. Nutrition information was gathered from the package label and manufacturer websites designed for school purchases. When this was not available, nutrition information was ascertained from an online retailer (e.g. Amazon or Walmart). To ensure that nutrition information was accurate for the year the product was sold, research assistants used the Internet Archive WayBack Machine (www.archive.org) to access manufacturer websites for the year in which the food was sold. Nutrition information was also checked against the John C. Stalker A-List for each year, which lists vending and snack products that meet the Massachusetts competitive food and beverage standards each year (http://www.johnstalkerinstitute.org/alist). For all analyses, nutrition information was calculated for the total package size, not per serving size.

\section{Reformulation and repackaging}

Foods and beverages were considered reformulated if their nutrition information changed from 2012 to 2013 
and/or 2014, but the product name and brand remained the same. Similarly, foods and beverages were considered repackaged if they were available in a different package size in 2013 and/or 2014 compared with what was available in 2012. Reformulation and repackaging could not be assessed for products that were sold only in one year (17\% of items).

\section{Look-alike foods}

For the present study, look-alike competitive foods were defined as reformulated items that had the same manufacturer and product name as items available in stores, but were made for distribution primarily in schools and were not available in grocery stores. Items were coded as lookalike when: (i) they were available in this sample of schools but were not for sale at Stop \& Shop (a large local supermarket chain) or Walmart (a large national chain); and (ii) they had the same manufacturer and product name as items available in stores. Look-alike foods often had similar packaging to the non-school versions, but this was not a requirement by our definition. For example, a popular brand of chips (crisps) made a reduced-fat version with similar packaging that was available for purchase in schools, but not for sale in stores. Research assistants evaluated whether reformulated foods were available at local and national grocery stores by searching for them on the stores' grocery shopping websites.

\section{Statistical analysis}

Multilevel linear regression was used to predict the mean change in nutrient composition (energy, total fat, saturated fat, Na, sugar, fibre, protein) from 2012 to 2013 and 2012 to 2014, adjusting for school level (middle or high school) and accounting for clustering of products within schools and districts. Models did not adjust for demographic covariates (percentage eligible for free/reduced-priced lunch, percentage racial/ethnic minority), as these were not statistically significantly associated with any nutrient outcomes.

To assess whether product reformulation changed during the study period, we calculated the percentage of reformulated foods and beverages in each year and used Pearson's $\chi^{2}$ to test for significant changes in reformulation between 2013 and 2014. Similarly, the percentages of repackaged foods and beverages were calculated and a $\chi^{2}$ test was performed. An additional sub-analysis used multilevel linear regression models to predict the changes in the package size of chips and beverages between 2012 and 2014, adjusting for school level. Changes in other categories of foods were not evaluated due to lack of standardized packaging. We additionally conducted a sensitivity analysis for selection bias among school districts that met or exceeded the state percentage of racial/ethnic minority students or students eligible for free/reduced-priced lunch, and compared the changes in nutritional profile of foods with those in the full analysis. All statistical analyses were conducted using the statistical software package Stata release 14 (2015).

\section{Results}

\section{Reformulation among foods and beverages}

Among the foods available two years following the implementation of the Massachusetts nutrition standards, $8 \cdot 1 \%$ were reformulated by 2013 and $17 \cdot 1 \%$ were reformulated by 2014 (Pearson's $\chi^{2}=4 \cdot 76, P=0 \cdot 03$; Table 1 ). Reformulation and repackaging were not widespread among beverages. Less than $1 \%$ of all beverages were reformulated in 2014 and less than $1 \%$ of beverages were repackaged over follow-up. However, the mean package size of beverages did decrease by 0.79 ounces $(23.4 \mathrm{ml})$ between 2012 and 2014, after adjusting for school level $(P=0.009)$.

More than one-quarter $(27 \cdot 2 \%)$ of the chips offered in schools after the law was implemented were reformulated. Chips remained the most frequent food category even after the implementation of the new law; roughly $30 \%$ of all competitive foods were chips in 2013 and 2014. The mean package size of chips decreased by 0.13 ounces $(3.7 \mathrm{~g})$ between 2012 and 2014, adjusting for school level $(P<0 \cdot 001)$, although this was not due to new package designs because only $<1 \%$ of chips were repackaged after baseline (Table 1).

Ice cream, popsicles and frozen treats were the second most reformulated food type (see online supplementary material, Supplemental Table 1, for examples of foods/beverages in each category); $17 \cdot 0 \%$ of foods in this category were reformulated after 2012 (Table 1). Some ice cream, popsicles and frozen treats were also repackaged: $12.6 \%$ by 2014 (Table 1 ). The proportion of ice cream, popsicles and frozen treats decreased from $17 \cdot 8 \%$ in 2012 to $4.0 \%$ of available foods in 2013 and $11.0 \%$ in 2014 . It should be noted that number of total available competitive foods in each school decreased over time as study participation declined, thus the denominator in all prevalence estimates decreased (available competitive foods: 2012, $n$ 1914; 2013, $n$ 1136; 2014, $n$ 805).

Cereals and breakfast bars and items were also reformulated: $10.8 \%$ in 2013 and an additional $11.4 \%$ by 2014 (Table 1). By 2014, 20.7\% of cereals and breakfast bars and items were also repackaged (Table 1). After the nutrition standards were implemented, cereals and breakfast bars and items became a larger proportion of the available competitive foods.

\section{Look-alike foods}

In this sample, $14.7 \%$ of all reformulated foods were lookalike foods, defined as reformulated items that had the same manufacturer and product name as items available in stores but were made for distribution primarily in schools 
Table 1 Number and percentage of foods reformulated and repackaged after implementation of Massachusetts competitive foods standards in $2012^{\star}, \dagger$

\begin{tabular}{|c|c|c|c|c|c|c|}
\hline \multirow[b]{2}{*}{ Food category } & \multicolumn{2}{|c|}{ Reformulated } & \multicolumn{2}{|c|}{ Repackaged } & \multicolumn{2}{|c|}{ Look-alike } \\
\hline & $n$ & $\%$ & $n$ & $\%$ & $n$ & $\%$ \\
\hline \multicolumn{7}{|c|}{ All foods ( $N$ 1941) } \\
\hline 2013 & 157 & $8 \cdot 1$ & 61 & $3 \cdot 1$ & 106 & 5.5 \\
\hline 2014 & 331 & $17 \cdot 1$ & 161 & $8 \cdot 3$ & 76 & 3.9 \\
\hline \multicolumn{7}{|l|}{ Chips (N 599) } \\
\hline 2013 & 88 & 14.7 & 1 & 0.2 & 81 & 13.5 \\
\hline 2014 & 163 & $27 \cdot 2$ & 4 & 0.7 & 63 & $10 \cdot 5$ \\
\hline \multicolumn{7}{|c|}{ Cereals, breakfast bars \& items ( $N 415)$} \\
\hline 2013 & 45 & $10 \cdot 8$ & 40 & $9 \cdot 6$ & 0 & - \\
\hline 2014 & 92 & $22 \cdot 2$ & 86 & $20 \cdot 7$ & 0 & - \\
\hline \multicolumn{7}{|c|}{ Crackers, popcorn \& pretzels ( $N 298$ ) } \\
\hline 2013 & 3 & 1.0 & 9 & 3.0 & 12 & 4.0 \\
\hline 2014 & 25 & 8.4 & 34 & 11.4 & 4 & 1.3 \\
\hline \multicolumn{7}{|c|}{ Cookies \& brownies ( $N 202)$} \\
\hline 2013 & 1 & 0.5 & 5 & 2.5 & 6 & 3.0 \\
\hline 2014 & 2 & 1.0 & 13 & $6 \cdot 4$ & 6 & 3.0 \\
\hline \multicolumn{7}{|c|}{ Ice cream \& frozen treats $(N 135)$} \\
\hline 2013 & 4 & 3.0 & 4 & 3.0 & 0 & - \\
\hline 2014 & 23 & $17 \cdot 0$ & 17 & $12 \cdot 6$ & 0 & - \\
\hline \multicolumn{7}{|c|}{ Other sweets ( $N$ 136) } \\
\hline 2013 & 14 & $10 \cdot 3$ & 2 & 1.5 & 0 & - \\
\hline 2014 & 23 & $17 \cdot 0$ & 2 & 1.5 & 0 & - \\
\hline \multicolumn{7}{|c|}{ Nuts \& salty snacks ( $N 88)$} \\
\hline 2013 & 0 & - & 0 & - & 0 & - \\
\hline 2014 & 0 & - & 0 & - & 0 & - \\
\hline \multicolumn{7}{|c|}{ Yoghurt \& cheese (N 52) } \\
\hline 2013 & 1 & 1.9 & 0 & - & 0 & - \\
\hline 2014 & 2 & 3.9 & 0 & - & 0 & - \\
\hline
\end{tabular}

*Foods were considered reformulated if the product name remained the same, but the nutritional content changed. Percentages of foods reformulated and repackaged from 2014 include items that were modified between 2012 and 2013 . For example, among all foods, 8.1\% were reformulated in 2013 and an additional $9.0 \%$ were reformulated in 2014 (total $17.1 \%$ by 2014 ). Look-alike foods are defined as reformulated items that were available in our sample of schools but were not for sale at local or national grocery stores. Look-alike foods have the same manufacturer and product name as items available in stores, but are made for distribution primarily in schools.

†These data were collected through photographic inventory of all competitive snacks sold in this sample of schools in Massachusetts. At baseline, thirty-six school districts participated; of those, twenty-eight districts participated in 2013 and twentyone districts in 2014.

and were not available in grocery stores. Look-alike foods made up almost one in five (19\%) of all chips available in schools.

\section{Nutrient changes to competitive foods and beverages}

At baseline, before the Massachusetts law took effect, $27 \%$ of competitive foods offered in this sample were chips, which had a mean of $157 \mathrm{kcal}(657 \mathrm{~kJ})$ and $6.7 \mathrm{~g}$ of fat $(1.0 \mathrm{~g}$ saturated) per package. Ice cream, popsicles and frozen treats were the second most widely available category of competitive foods (18\%) in 2012, and had a mean of $163 \mathrm{kcal}(682 \mathrm{~kJ})$ and $6.4 \mathrm{~g}$ of fat $(3.8 \mathrm{~g}$ saturated) per package.

After the standards were implemented, most schools were compliant with nutrient cut-offs. The standards placed a limit of $200 \mathrm{kcal}(837 \mathrm{~kJ})$ on snack items, and by 2014, 9.3\% of items exceeded this limit. The reforms also required a limit on percentage of energy from fat $(\leq 35 \%$ total energy from fat, $<10 \%$ total energy from saturated fat), which were exceeded by $7 \cdot 8$ and $10.3 \%$ of foods and beverages, respectively. By 2014 , only $1.4 \%$ of milk beverages had greater than the maximum amount of $22 \mathrm{~g}$ sugar. With respect to sugar and $\mathrm{Na}$ limits, $6.8 \%$ were $>35 \%$ sugar by weight and $14.7 \%$ had $>200 \mathrm{mg} \mathrm{Na}$. Energy, total fat, saturated fat, $\mathrm{Na}$ and sugar decreased and fibre increased in competitive foods overall (Table 2) and when stratified by food category (all $P<0.05$ for all categories; Table 3), except among nuts and salty snacks. Among the beverages available after 2012, mean energy, $\mathrm{Na}$ and sugar decreased and mean protein per beverage increased (Table 2). The mean energy in the 'other' category of competitive beverages, which included lemonade and soda, decreased from $108 \mathrm{kcal}(452 \mathrm{~kJ})$ in 2012 to $73 \mathrm{kcal}(305 \mathrm{~kJ})$ in 2014 , and the mean sugar content per container decreased from 25 to $16 \mathrm{~g}$.

\section{Discussion}

The present study is the first to evaluate the extent of competitive food reformulation in response to the implementation of new competitive food standards in middle schools and high schools. The results of the study indicate 
Table 2 Mean nutrients and change in nutrient profiles of all competitive foods and beverages in thirty-six Massachusetts school districts before (2012) and after (2013-2014) implementation of competitive food and beverage standards ${ }^{\star}, \dagger, \ddagger$

\begin{tabular}{|c|c|c|c|c|c|c|c|}
\hline & Energy (kcal)§ & Total fat $(\mathrm{g})$ & Saturated fat $(\mathrm{g})$ & $\mathrm{Na}(\mathrm{mg})$ & Sugar (g) & Fibre $(\mathrm{g})$ & Protein $(\mathrm{g})$ \\
\hline \multicolumn{8}{|l|}{ All foods } \\
\hline 2012 & $162 \cdot 2$ & 5.8 & 1.8 & 171.6 & 9.5 & 1.2 & 2.5 \\
\hline 2013 & 139.5 & 4.5 & 0.9 & $156 \cdot 8$ & $7 \cdot 3$ & $1 \cdot 7$ & $2 \cdot 5$ \\
\hline 2014 & $135 \cdot 2$ & 4.3 & 0.9 & $146 \cdot 1$ & $7 \cdot 1$ & 1.6 & 2.3 \\
\hline Change & $-22 \cdot 7$ & $-1 \cdot 3$ & -0.8 & $-19 \cdot 3$ & $-2 \cdot 3$ & 0.4 & -0.1 \\
\hline $95 \% \mathrm{Cl}$ & $-29 \cdot 1,-16 \cdot 4$ & $-1 \cdot 9,-0.8$ & $-0.9,-0.6$ & $-33 \cdot 8,-4 \cdot 8$ & $-3 \cdot 3,-1 \cdot 3$ & $0.3,0.6$ & $-0.3,0.1$ \\
\hline \multicolumn{8}{|c|}{ All beverages } \\
\hline 2012 & 83.2 & 0.2 & 0.1 & $82 \cdot 6$ & $17 \cdot 4$ & 0.0 & 1.5 \\
\hline 2013 & $54 \cdot 1$ & 0.2 & 0.1 & 53.4 & 9.8 & 0.0 & 1.9 \\
\hline 2014 & $57 \cdot 3$ & 0.3 & 0.2 & $73 \cdot 0$ & $9 \cdot 3$ & 0.0 & $2 \cdot 8$ \\
\hline Change & $-27 \cdot 34$ & 0.13 & 0.07 & $-12 \cdot 24$ & -7.97 & 0.0 & 0.95 \\
\hline $95 \% \mathrm{Cl}$ & $-38 \cdot 7,-16 \cdot 0$ & $0.0,0.2$ & $0.0,0.1$ & $-22 \cdot 8,-1 \cdot 7$ & $-10 \cdot 3,-5 \cdot 6$ & $-0.1,0.1$ & $0.3,1 \cdot 6$ \\
\hline
\end{tabular}

*Multilevel linear regression models were used to find the mean change in each nutrient comparing 2012 and 2014 (and its $\mathrm{Cl}$ ), adjusting for school level (middle or high school) and modelling clustering of items within schools and districts. At baseline, thirty-six school districts participated; of those, twenty-eight districts participated in 2013 and twenty-one districts in 2014.

†The means reported for each nutrient in each year are unadjusted for school level.

¥These data were collected through photographic inventory of all competitive snacks sold in this sample of schools in Massachusetts. Nutrition information was gathered from the package label and manufacturer websites designed for school purchases. When this was not available, nutrition information was ascertained from an online retailer.

$\S$ To convert to kJ, multiply kcal values by 4.184 .

that product reformulation did play a role in helping schools make nutritional improvements after the competitive foods standards were passed. These product reformulations occurred after and perhaps in response to the competitive food regulations in Massachusetts, as well as potentially in anticipation of the national Smart Snacks law. Reformulation was uncommon among beverages, but a higher percentage of beverages were compliant with state nutrition standards at baseline ${ }^{(12)}$, and since skimmed milk, $100 \%$ juice and plain water were available at baseline these products were not considered reformulated. There were no reformulations of sports drinks and sugarsweetened beverages, which categorically would not be allowed for sale under the law.

A previous simulation study estimated that reformulating a competitive prepared food could improve students' diet quality, but it did not measure actual nutritional changes in available foods ${ }^{(16)}$. Another simulated estimate among adults found that food reformulation may reduce diseaserelated mortality by up to $5 \cdot 5 \%$, indicating its potential to improve the public's health if used on a broad scale ${ }^{(17)}$. Reformulated meals have had a positive impact on healthy food consumption for children ${ }^{(18)}$, which indicates that this may be one promising strategy for schools trying to increase their compliance with the standards.

Of the foods that were reformulated, $15 \%$ were lookalike versions that were compliant with the standards but were not currently available for sale outside schools. This indicates that food manufacturers were able to successfully respond to strict state nutrition standards by changing the nutrient profile of foods within a short time frame, but these foods were not yet available on the wider market. A recent study found that parents and students cannot distinguish between healthier look-alike items and store versions of the same brands in terms of expected taste or healthfulness, and they have a similar intent to purchase ${ }^{(15)}$. Manufacturers of look-alike foods and noncompliant foods are thus able to market to children in schools, potentially encouraging them to establish brand preferences for unhealthy products sold outside school with consumers' expectations that they would have the same nutritional qualities as the snacks available at schools $^{(19,20)}$. Although it is possible that brand preferences established outside school may lead children to purchase the reformulated look-alike versions in school, it is also possible that having these brands available may hurt schools' credibility when teaching nutrition and wellness because of their association with less healthy versions $^{(15)}$. This issue would be avoided if schools sold only new, compliant products or if reformulated versions had clearly different packaging.

Changes to package sizes also helped school districts improve the nutritional quality of competitive foods. Package sizes decreased overall (with nutrient density remaining unchanged); the size of chip bags decreased by 0.13 ounces $(3.7 \mathrm{~g})$ between 2012 and 2014. The present data indicate that some foods were repackaged $(8.3 \%$ by 2014) to meet the competitive food standards. Many smaller package sizes were available at baseline but became more widely used after the standards were implemented, and these items were thus not counted as repackaged. The decrease in observed package size for beverages demonstrates that this component of the law was effectively implemented (8 fluid ounces $(237 \mathrm{ml}$ ) for milk and 4 fluid ounces (118 $\mathrm{ml}$ ) for juice).

Among this sample of Massachusetts schools, the implementation of nutrition standards for competitive foods and beverages was associated with improvements to the nutrient profile of foods and beverages, due in part to food manufacturers reformulating and repackaging products. The findings of this analysis support existing evidence that setting strict nutrition standards can 
Table 3 Mean nutrients and change in nutrients from competitive foods and beverages available at thirty-six Massachusetts school districts from before (2012) to after (2014) implementation of competitive food and beverage standards, according to food/beverage category ${ }^{*}, \dagger, \ddagger$

\begin{tabular}{|c|c|c|c|c|c|c|c|}
\hline & Energy $(\mathrm{kcal}) \S$ & Total fat $(\mathrm{g})$ & Saturated fat (g) & $\mathrm{Na}(\mathrm{mg})$ & Sugar (g) & Fibre (g) & Protein $(\mathrm{g})$ \\
\hline \multicolumn{8}{|l|}{ Chips } \\
\hline 2012 & 156.9 & $6 \cdot 7$ & 1.0 & 213.4 & 1.8 & 1.6 & $2 \cdot 3$ \\
\hline 2014 & $130 \cdot 2$ & 5.0 & 0.6 & 178.4 & 1.4 & 1.6 & $2 \cdot 0$ \\
\hline Change & $-24 \cdot 3$ & -1.6 & -0.4 & -31.0 & -0.4 & -0.0 & -0.2 \\
\hline $95 \% \mathrm{Cl}$ & $-32 \cdot 6,-16 \cdot 0$ & $-2 \cdot 3,-0.9$ & $-0.4,-0.2$ & $-40 \cdot 7,-21 \cdot 3$ & $-0.6,-0.2$ & $-0.1,0.1$ & $-0.4,-0.1$ \\
\hline \multicolumn{8}{|c|}{ Cereals, breakfast bars \& items } \\
\hline 2012 & 190.4 & $5 \cdot 0$ & 1.5 & 169.5 & $15 \cdot 0$ & 2.5 & $3 \cdot 1$ \\
\hline 2014 & 161.3 & 3.5 & 0.8 & $152 \cdot 4$ & 11.8 & 2.5 & 2.7 \\
\hline Change & $-16 \cdot 7$ & -1.2 & -0.5 & $-8 \cdot 3$ & $-2 \cdot 1$ & 0.1 & $-0 \cdot 1$ \\
\hline $95 \% \mathrm{Cl}$ & $-31 \cdot 6,-1 \cdot 8$ & $-1 \cdot 8,-0.6$ & $-0.7,-0.3$ & $-21 \cdot 5,5 \cdot 0$ & $-3.6,-0.7$ & $-0.3,0.4$ & $-0.9,0.6$ \\
\hline \multicolumn{8}{|c|}{ Crackers, popcorn \& pretzels } \\
\hline 2012 & $170 \cdot 1$ & 6.5 & 1.6 & $298 \cdot 2$ & $3 \cdot 1$ & 1.0 & $3 \cdot 2$ \\
\hline 2014 & $127 \cdot 6$ & 4.4 & 0.8 & 201.8 & 2.5 & 1.4 & $2 \cdot \overline{6}$ \\
\hline Change & -31.2 & $-2 \cdot 0$ & -0.7 & -91.6 & -0.6 & 0.4 & $-0 \cdot 7$ \\
\hline $95 \% \mathrm{Cl}$ & $-58.9,-23.5$ & $-2 \cdot 9,-1 \cdot 1$ & $-1 \cdot 0,-0.4$ & $-127 \cdot 8,-55.4$ & $-1 \cdot 3,0.2$ & $0.0,0.7$ & $-1 \cdot 0,-0.3$ \\
\hline \multicolumn{8}{|c|}{ Cookies \& brownies } \\
\hline 2012 & 168.0 & $6 \cdot 8$ & $2 \cdot 2$ & $139 \cdot 2$ & 11.9 & 1.2 & $2 \cdot 0$ \\
\hline 2014 & $132 \cdot 1$ & 4.6 & $1 . \overline{5}$ & $112 \cdot 6$ & 9.3 & $1 . \overline{6}$ & $2 \cdot 0$ \\
\hline Change & -26.5 & -1.4 & -0.6 & -24.9 & $-2 \cdot 0$ & 0.3 & $0 \cdot 1$ \\
\hline $95 \% \mathrm{Cl}$ & $-45 \cdot 0,-8 \cdot 0$ & $-2 \cdot 9,-0.0$ & $-1.4,0.3$ & $-43 \cdot 8,-5 \cdot 9$ & $-3 \cdot 9,-0.1$ & $-0.0,0.6$ & $-0.0,0.5$ \\
\hline \multicolumn{8}{|c|}{ Ice cream \& frozen treats } \\
\hline 2012 & $162 \cdot 7$ & $6 \cdot 4$ & 3.8 & $69 \cdot 2$ & $17 \cdot 6$ & 0.2 & $2 \cdot 2$ \\
\hline 2014 & $118 \cdot 2$ & $2 \cdot 6$ & 1.6 & $47 \cdot 7$ & $15 \cdot 7$ & 0.5 & 1.6 \\
\hline Change & -41.6 & -3.6 & $-2 \cdot 2$ & $-17 \cdot 6$ & $-1 \cdot 7$ & 0.4 & -0.6 \\
\hline $95 \% \mathrm{Cl}$ & $-58 \cdot 3,-25 \cdot 0$ & $-5 \cdot 1,-2 \cdot 2$ & $-3 \cdot 2,-1 \cdot 2$ & $-28 \cdot 3,-6 \cdot 9$ & $-3 \cdot 1,-0 \cdot 2$ & $-0.1,0.9$ & $-0.9,-0.2$ \\
\hline \multicolumn{8}{|c|}{ Other sweets } \\
\hline 2012 & 129.8 & $2 \cdot 3$ & 0.8 & $62 \cdot 2$ & $15 \cdot 2$ & 0.4 & 1.0 \\
\hline 2014 & 127.9 & $2 \cdot 3$ & 0.9 & 63.5 & $16 \cdot 4$ & 0.9 & $1 \cdot 1$ \\
\hline Change & $-25 \cdot 1$ & -1.3 & -0.0 & $-36 \cdot 2$ & 1.3 & 0.5 & -0.4 \\
\hline $95 \% \mathrm{Cl}$ & $-49.5,-0.7$ & $-2 \cdot 9,0.2$ & $-0.6,0.6$ & $-69 \cdot 0,-3 \cdot 4$ & $-2 \cdot 4,5 \cdot 0$ & $0.1,0.9$ & $-1 \cdot 1,0.2$ \\
\hline \multicolumn{8}{|c|}{ Nuts \& salty snacks } \\
\hline 2012 & 134.9 & 6.6 & 1.3 & $215 \cdot 7$ & $2 \cdot 4$ & 1.0 & $3 \cdot 1$ \\
\hline 2014 & 159.4 & 11.9 & 1.5 & $112 \cdot 1$ & 4.9 & $2 \cdot 2$ & 4.7 \\
\hline Change & $24 \cdot 1$ & $5 \cdot 2$ & 0.2 & $-78 \cdot 7$ & $2 \cdot 6$ & 1.2 & 1.6 \\
\hline $95 \% \mathrm{Cl}$ & $2 \cdot 7,45 \cdot 4$ & $1.5,9.0$ & $-0.4,0.9$ & $-124 \cdot 9,-32 \cdot 7$ & $0.9,4.3$ & $0.8,1.7$ & $-0.1,3.2$ \\
\hline \multicolumn{8}{|c|}{ Yoghurt \& cheese } \\
\hline 2012 & 133.3 & $2 \cdot 0$ & $1 \cdot 1$ & 102.5 & $18 \cdot 3$ & 0.0 & $5 \cdot 2$ \\
\hline 2014 & 117.5 & 0.5 & 0.4 & 85.5 & $17 \cdot 2$ & 0.0 & $5 \cdot 1$ \\
\hline Change & -31.1 & $-1 \cdot 1$ & -0.6 & $-14 \cdot 1$ & -4.2 & -0.0 & -0.2 \\
\hline $95 \% \mathrm{Cl}$ & $-59.7,-2.5$ & $-1 \cdot 9,-0.2$ & $-1 \cdot 0,-0 \cdot 1$ & $-32 \cdot 9,4 \cdot 7$ & $10 \cdot 4,2 \cdot 0$ & $-0.1,0.0$ & $-1 \cdot 1,0.7$ \\
\hline \multicolumn{8}{|l|}{ Milk } \\
\hline 2012 & $125 \cdot 7$ & $1 \cdot 1$ & 0.7 & $165 \cdot 2$ & $17 \cdot 6$ & 0.0 & 8.9 \\
\hline 2014 & $110 \cdot 7$ & 0.9 & 0.5 & $153 \cdot 0$ & $15 \cdot 2$ & $0 \cdot 1$ & $8 \cdot 0$ \\
\hline Change & $-12 \cdot 8$ & -0.2 & -0.1 & -13.9 & $-2 \cdot 4$ & 0.0 & -0.8 \\
\hline $95 \% \mathrm{Cl}$ & $-20 \cdot 9,-6 \cdot 7$ & $-0.3,0.0$ & $-0.2,0.0$ & $-21 \cdot 1,-2 \cdot 1$ & $-3 \cdot 5,-1 \cdot 2$ & $-0.1,0.1$ & $-1.3,-0.4$ \\
\hline \multicolumn{8}{|c|}{ Flavoured water } \\
\hline 2012 & $6 \cdot 2$ & - & - & $56 \cdot 0$ & 1.4 & - & - \\
\hline 2014 & 1.3 & - & - & 29.4 & 0.2 & - & - \\
\hline Change & $-2 \cdot 4$ & - & - & $-26 \cdot 2$ & -0.5 & - & - \\
\hline $95 \% \mathrm{Cl}$ & $-9 \cdot 0,4 \cdot 2$ & - & - & $-47 \cdot 1,-5 \cdot 4$ & $-2 \cdot 1,1 \cdot 1$ & - & - \\
\hline \multicolumn{8}{|l|}{ Juice } \\
\hline 2012 & $136 \cdot 5$ & - & - & 19.7 & $31 \cdot 1$ & 0.0 & 0.4 \\
\hline 2014 & $101 \cdot 2$ & - & - & 13.2 & $22 \cdot 3$ & 0.0 & 0.4 \\
\hline Change & $-30 \cdot 3$ & - & - & $-7 \cdot 3$ & $-7 \cdot 2$ & -0.0 & 0.0 \\
\hline $95 \% \mathrm{Cl}$ & $-43 \cdot 8,-16 \cdot 8$ & - & - & $-10 \cdot 6,-4 \cdot 0$ & $-10 \cdot 5,-3.8$ & $-0.1,0.0)$ & $-0.2,0.2$ \\
\hline \multicolumn{8}{|c|}{ Sports drinks } \\
\hline 2012 & $52 \cdot 2$ & - & - & 143.7 & $12 \cdot 2$ & - & - \\
\hline 2014 & $47 \cdot 1$ & - & - & 159.7 & $6 \cdot 9$ & - & - \\
\hline Change & $4 \cdot 3$ & - & - & 20.8 & $-2 \cdot 0$ & - & - \\
\hline $95 \% \mathrm{Cl}$ & $-20 \cdot 2,28 \cdot 9$ & - & - & $-14 \cdot 8,56 \cdot 4$ & $-10.8,6 \cdot 9$ & - & - \\
\hline Other bever & & & & & & & \\
\hline 2012 & $108 \cdot 2$ & $0 \cdot 1$ & 0.0 & $71 \cdot 1$ & $25 \cdot 1$ & $0 \cdot 1$ & 0.4 \\
\hline 2014 & $72 \cdot 7$ & 0.2 & 0.1 & 99.7 & $15 \cdot 7$ & 0.2 & 0.7 \\
\hline Change & -28.5 & 0.2 & 0.1 & 9.1 & -8.5 & 0.2 & 0.5 \\
\hline $95 \% \mathrm{Cl}$ & $-63 \cdot 2,6 \cdot 2$ & $-0.1,0.4$ & $-0.1,0.3$ & $-19.5,37.7$ & $-16 \cdot 7,-0.4$ & $-0.2,0.5$ & $-0.8,1.8$ \\
\hline
\end{tabular}

*Multilevel models were used to find the mean change in each nutrient comparing 2012 and 2014 (and its $\mathrm{Cl}$ ), adjusting for school level (middle or high school) and clustering of items within schools and districts. At baseline, thirty-six school districts participated; of those, twenty-eight districts participated in 2013 and twenty-one districts in 2014.

†The means reported for each nutrient in each year are unadjusted for school level.

$\ddagger$ These data were collected via photographic inventory of all competitive snacks sold in this sample of schools in Massachusetts. Nutrition information was gathered from the package label and manufacturer websites designed for school purchases. When this was not available, nutrition information was ascertained from an online retailer.

$\S$ To convert to kJ, multiply kcal values by $4 \cdot 184$. 
positively impact the nutritional profile of school food $^{(21-23)}$. This nutritional information expands upon previous research that showed schools had on average $60 \%$ of foods and $78 \%$ of beverages compliant with the nutritional guidelines two years after implementation of the standards ${ }^{(12)}$. Therefore, the nutritional improvements observed in the present study suggest that even imperfect compliance with the law positively impacted the nutritional quality of competitive foods and beverages.

The strengths of the present study include data collection from both pre- and post-implementation of the competitive food law and its two-year follow-up to observe immediate and ongoing response to the policy. The study also has limitations that are important to identify. First, schools in the study may not be racially/ethnically or economically representative of all schools in Massachusetts, and schools in Massachusetts may not be generalizable to the rest of the country. However, in a sensitivity analysis among the few school districts in the study sample that met or exceeded the state percentage of racial/ethnic minority students or students eligible for free/reducedpriced lunch, results for changes in nutritional profile of foods were similar to those in the full sample. The study also did not capture non-packaged competitive food items such as fresh fruits and vegetables because they were served in non-standardized portions. These unpackaged foods were typically sold as part of the school meal programme and were not usually intended to be sold as competitive foods. We also did not capture competitive foods that were sold in the morning for breakfast, although we were able to document competitive foods sold in vending machines that would be available throughout the day. The present study did not analyse data on individual consumption or purchasing behaviour. Previous analyses using NOURISH study data did find decreases in schools' competitive foods sales. However, students compensated for decreased competitive food purchases by selecting the healthier school meals, which overall is beneficial to both children and schools ${ }^{(13)}$. Future NOURISH studies will examine how product reformulation impacts individual student consumption as well. Lastly, the present study's estimate of product reformulation is an underestimate of total reformulation, as it only assessed reformulation between 2012 and 2014. It is likely that products were reformulated prior to 2012, especially in light of Massachusetts previously considering competitive foods nutrition standards ${ }^{(10)}$.

Given that the national Smart Snacks standards are very similar to the Massachusetts competitive foods standards, national brands that reformulated products in this sample may reformulate more products to fit national standards. Thus, results of the present study suggest the Smart Snacks in School standards may have a similar impact on the nutritional profile of competitive foods nationwide. Because frequently packaging for reformulated versions of products is very similar to less healthy versions, researchers and state governments should continue to monitor the nutritional quality of competitive foods to ensure that they comply with the competitive foods standards. More broadly, it will also be important to investigate the contribution of competitive foods to children's overall diet quality, as well as nutritional reforms to other food environments.

\section{Acknowledgements}

Acknowledgements: The authors thank the participating school districts and research assistants, especially Chloe Fishman and Kia Turner, who made this study possible. Financial support: Funding for the Nutrition Opportunities to Understand Reforms Involving Student Health (NOURISH) study was provided by Harvard Catalyst and the Healthy Eating Research Program of the Robert Wood Johnson Foundation. J.F.W.C. was supported by the Nutrition Epidemiology of Cancer Education and Career Developing Program (grant number R25 CA 098566). M.T.G.-F. is supported by the Agency for Healthcare Research and Quality (grant number T32HS000055). The funding agencies had no involvement in the study design, interpretation of data, article preparation, or the decision to submit the article for publication. The content is solely the responsibility of the authors and does not necessarily represent the official views of the Agency for Healthcare Research and Quality. Conflict of interest: None. Authorship: J.L.J. formulated the research question, analysed the data and wrote the article. J.F.W.C., M.T.G.-F., J.A.H., L.R., R.C., L.S. and E.B.R. designed the study and carried it out. All authors read and edited the manuscript. Ethics of buman subject participation: This study was conducted according to the guidelines laid down in the Declaration of Helsinki and all procedures involving human subjects were approved by the Harvard University Institutional Review Board. Written informed consent was obtained from all subjects.

\section{Supplementary material}

To view supplementary material for this article, please visit https://doi.org/10.1017/\$1368980017003445

\section{References}

1. US Department of Agriculture (2013) National School Lunch Program and School Breakfast Program: nutrition standards for all foods sold in school as required by the Healthy, Hunger-Free Kids Act of 2010. 7 CFR Parts 210-220. https:// www.gpo.gov/fdsys/granule/CFR-2013-title7-vol4/CFR-2013title7-vol4-part210 (accessed November 2017).

2. Turner LR \& Chaloupka FJ (2012) Student access to competitive foods in elementary schools: trends over time and regional differences. Arch Pediatr Adolesc Med 166, 164-169. 
3. Fox MK, Gordon A, Nogales R et al. (2009) Availability and consumption of competitive foods in US public schools. J Am Diet Assoc 109, Suppl. 2, S57-S66.

4. Sanchez-Vaznaugh EV, Sanchez BN, Baek J et al. (2010) 'Competitive' food and beverage policies: are they influencing childhood overweight trends? Health Aff (Millwood) 29, 436-446.

5. Taber DR, Chriqui JF, Perna FM et al. (2012) Weight status among adolescents in States that govern competitive food nutrition content. Pediatrics 130, 437-444.

6. Bruemmer B, Krieger J, Saelens BE et al. (2012) Energy, saturated fat, and sodium were lower in entrees at chain restaurants at 18 months compared with 6 months following the implementation of mandatory menu labeling regulation in King County, Washington. J Acad Nutr Diet 112, 1169-1176.

7. Namba A, Auchincloss A, Leonberg BL et al. (2013) Exploratory analysis of fast-food chain restaurant menus before and after implementation of local calorie-labeling policies, 2005-2011. Prev Chronic Dis 10, E101.

8. Mozaffarian D, Jacobson MF \& Greenstein JS (2010) Food reformulations to reduce trans fatty acids. NEngl J Med $\mathbf{3 6 2}$, 2037-2039.

9. Otite FO, Jacobson MF, Dahmubed A et al. (2013) Trends in trans fatty acids reformulations of US supermarket and brand-name foods from 2007 through 2011. Prev Chronic Dis 10, E85.

10. Commonwealth of Massachusetts (2017) General Laws, Part I, Title XVI, Chapter 111, Section 223: Nutritional standards for sale or provision of foods or beverages in public schools; school wellness advisory committees; food safety inspections at public schools. https://malegislature.gov/Laws/ GeneralLaws/PartI/TitleXVI/Chapter111/Section223 (accessed November 2017).

11. Hoffman JA, Rosenfeld L, Schmidt N et al. (2015) Implementation of competitive food and beverage standards in a sample of Massachusetts schools: the NOURISH study (Nutrition Opportunities to Understand Reforms Involving Student Health). J Acad Nutr Diet 115, 1299-1307.e2.

12. Gorski MT, Cohen JF, Hoffman JA et al. (2016) Impact of nutrition standards on competitive food quality in Massachusetts middle and high schools. Am J Public Health 106, 1101-1108.
13. Cohen JF, Gorski MT, Hoffman JA et al. (2016) Healthier standards for school meals and snacks: impact on school food revenues and lunch participation rates. Am J Prev Med 51, 485-492.

14. Rosenfeld LE, Cohen JF, Gorski MT et al. (2017) How do we actually put smarter snacks in schools? NOURISH (Nutrition Opportunities to Understand Reforms Involving Student Health) conversations with food-service directors. Public Health Nutr 20, 556-564.

15. Harris JL, Hyary M \& Schwartz MB (2016) Effects of offering look-alike products as smart snacks in schools. Child Obes 12, 432-439.

16. Hur IY, Marquart L \& Reicks M (2014) Nutrient intakes among children and adolescents eating usual pizza products in school lunch compared with pizza meeting HealthierUS school challenge criteria. J Acad Nutr Diet 114, 768-773.

17. Leroy P, Requillart V, Soler LG et al. (2016) An assessment of the potential health impacts of food reformulation. Eur $J$ Clin Nutr 70, 694-699.

18. Tritt A, Reicks M \& Marquart L (2015) Reformulation of pizza crust in restaurants may increase whole-grain intake among children. Public Health Nutr 18, 1407-1411.

19. Cornwell TB, McAlister AR \& Polmear-Swendris N (2014) Children's knowledge of packaged and fast food brands and their BMI. Why the relationship matters for policy makers. Appetite 81, 277-283.

20. Terry-McElrath YM, Turner L, Sandoval A et al. (2014) Commercialism in US elementary and secondary school nutrition environments: trends from 2007 to 2012. JAMA Pediatr 168, 234-242.

21. Taber DR, Chriqui JF \& Chaloupka FJ (2012) Differences in nutrient intake associated with state laws regarding fat, sugar, and caloric content of competitive foods. Arch Pediatr Adolesc Med 166, 452-458.

22. Samuels SE, Hutchinson KS, Craypo L et al. (2010) Implementation of California state school competitive food and beverage standards. J Sch Health 80, 581-587.

23. Chriqui JF, Pickel M \& Story M (2014) Influence of school competitive food and beverage policies on obesity, consumption, and availability: a systematic review. JAMA Pediatr 168, 279-286. 